\title{
Adsorption of Lipid-containing Bacteriophages PR4 and PRD1 to Pili Determined by a P-1 Incompatibility Group Plasmid
}

\author{
By DAVID E. BRADLEY AND DORIS R. COHEN \\ Faculty of Medicine, Memorial University of Newfoundland, St John's, \\ Newfoundland, Canada $A$ I $B{ }_{3} V 6$
}

(Received I4 September 1976)

\section{INTRODUCTION}

Bacteriophages PRDI (Olsen, Siak \& Gray, 1974) and PR4 (Stanisich, I974; Bradley \& Rutherford, 1975) belong to a group of lipid-containing viruses which lyse bacteria harbouring any drug resistance plasmid within the incompatibility groups P-I (originally P, see Shahrabadi, Bryan \& Van Den Elzen, 1975; Jacoby, 1977), N or W. The morphologically identical viruses possess a $65 \mathrm{~nm}$ diameter head, which is probably icosahedral, and a $60 \mathrm{~nm}$ tail, originally thought to be absent on PRDI (Olsen et al., I974). Until recently, both phages were believed to adsorb only to cell-wall receptors, and not to plasmid-determined pili (Olsen et al., I974; Bradley, 1974). The chemical nature of a somatic receptor determined by RPI, a P-I group plasmid, has been described by Olsen, Siak \& Shipley (I977). However, Bradley (1976) has shown that PR4 adsorbs to the tips of pili determined by W incompatibility group plasmids. In view of this, it was considered possible that previous failures to observe lipid phage virions adsorbed to pili determined by P-I plasmids (P-I pili) was due to the adverse effects of the electron microscope specimen preparation process used. The present communication describes the results of a different technical approach, and discusses the nature of the lipid phage receptor.

\section{METHODS}

Bacteria and bacteriophages were very kindly supplied as follows: Escherichia col CR34 (RPI) by R. H. Olsen (Olsen \& Shipley, I973); Salmonella typhimurium LT2 strain SQI I 39 by R. Bradley; phages PRRI (Olsen \& Thomas, I973) and PRDI (Olsen et al, 1974) by R. H. Olsen. Phage PR4 (Stanisich, 1974; Bradley \& Rutherford, 1975) was originally supplied by V. Stanisich. Salmonella typhimurium SQI 39 (RPI) was constructed by standard mating procedures from $E$. coli $\mathrm{CR} 34$ (RPI) and $S$. typhimurium SQI I39. Bacteriophages were prepared as high titre suspensions in broth by the extraction of plates of host bacteria that had been confluently lysed.

Preparation and electron microscopy of adsorption mixtures of bacteriophages and bacteria. We have modified the method of Crawford \& Gesteland (1964) who used prior adsorption of RNA bacteriophages to the sides of $F$ pili to demonstrate filamentous phage adsorption to the tips in the electron microscope. A small amount of $R+$ bacterial culture (shaken for 4 to $5 \mathrm{~h}$ at $37^{\circ} \mathrm{C}$, then static for $2 \mathrm{~h}$ ) was placed with a micropipette on a support grid held in clamped forceps. An equal volume of RPI-specific RNA phage PRRI suspension, titre $\mathrm{I} \times 10^{11}$ plaque-forming units (p.f.u.) $\mathrm{ml}^{-1}$, was added. After $10 \mathrm{~min}$ at room temperature (the forceps with the grid were placed in a covered dish with a little water to prevent drying), the same volume of PR4 or PRD I suspension $\left(2 \times 10^{10}\right.$ p.f.u. $\left.\mathrm{ml}^{-1}\right)$ was added. After a further 
Io min, the grid was washed by floating it on $0.1 \mathrm{M}$-ammonium acetate solution, and then negatively stained with $0.15 \%(\mathrm{w} / \mathrm{v})$ sodium phosphotungstate solution. A second method, which will be referred to as the plate method, consisted of placing drops of RNA and lipid phages sequentially ( 5 min intervals) at the same place on the surface of an overnight softagar plate of the host organism. After a further $5 \mathrm{~min}$, a grid was placed on the wet area with its carbon film downwards for about I min. It was then washed and negatively stained. Both methods were used for strains of E. coli and S. typhimurium, but neither was successful for strains of Pseudomonas aeruginosa, presumably because metabolic products from the organisms prevented usable negative staining. Even with $E$. coli and $S$. typhimurium, the quality of the negative staining suffered to some extent, particularly with the plate method. This was believed to be due to the adsorption to the support film of extraneous material such as agar, which would affect the spreading of the sodium phosphotungstate.

\section{RESULTS}

It was confirmed by the spot test that phages PRDI, PR4 and PRRI plaqued on E. coli CR34 (RPI) but not on E. coli CR34; thus sensitivity to the phages was conferred by RPI. In addition, it has been established, using E. coli CR34 (RPI), that the PRRI receptor is the P-I pilus determined by the plasmid (Bradley, I974).

PRDI virions adsorbed to the cell surface [Fig. I (plate method), left] and to the tip of a P-I pilus (Fig. I, right) on E. coli CR34 (RPI). The smaller RNA phage virions can just be detected (arrowed). They are clearer on the sides of the pili (see Bradley, I974) in Fig. 2, which shows PRRI and PR4 virions adsorbed to pili on S. typhimurium SQII39 (RPI); the top virion has probably become detached from the pilus on the left during drying. The lower PR4 virion is attached to the tip of a very short pilus. Longer pili from the same adsorption mixture are shown in Fig. 3. Few PRRI virions (arrowed) are present on the longer pilus, so that adequate space is available for lipid phages to adsorb to the sides of the filament, but this did not occur with any of the many phage plus pilus complexes observed. Tails were not visible on adsorbed virions, the site of attachment being an apex of the capsid. It is possible that barely detectable apical capsomeres, which have been illustrated elsewhere (Olsen et al., I974), are involved in adsorption.

The frequency of adsorption to P-I pilus tips was assessed by counting phages and pili on cells from an adsorption mixture of E. coli $\mathrm{CR}_{34}(\mathrm{RPI})$ with phages PRRI and PR4 (not illustrated). Virions and pili were scored only if they were visible beyond the cell edge because of poor negative staining on the cell surface. A sample of 50 cells had a total of 46 pili of which 20 had PR4 virions at their tips. There were 548 virions on the cell surface not visibly attached to pili (I I virions/cell). This level was much higher than can be accounted for by non-specific adsorption: only 0.88 virions/cell were found on the surface of $E$. coli CR34 under similar adsorption conditions (Bradley, 1976). Clearly, the number of virions on pilus tips is significant, although many more were located at the cell surface.

To determine the effect of PRRI adsorption on the numbers of pili on E. coli CR34 (RPI), an adsorption mixture of phage and bacteria was prepared and examined without the addition of lipid phage. Control grids were made by using broth in place of the PRRI suspension. Pili projecting beyond the cell edges were counted on 100 cells. The average number of pili with no PRRI adsorbed was 0.08 pili/cell, but after PRRI adsorption, I 37 pili/cell were present. 

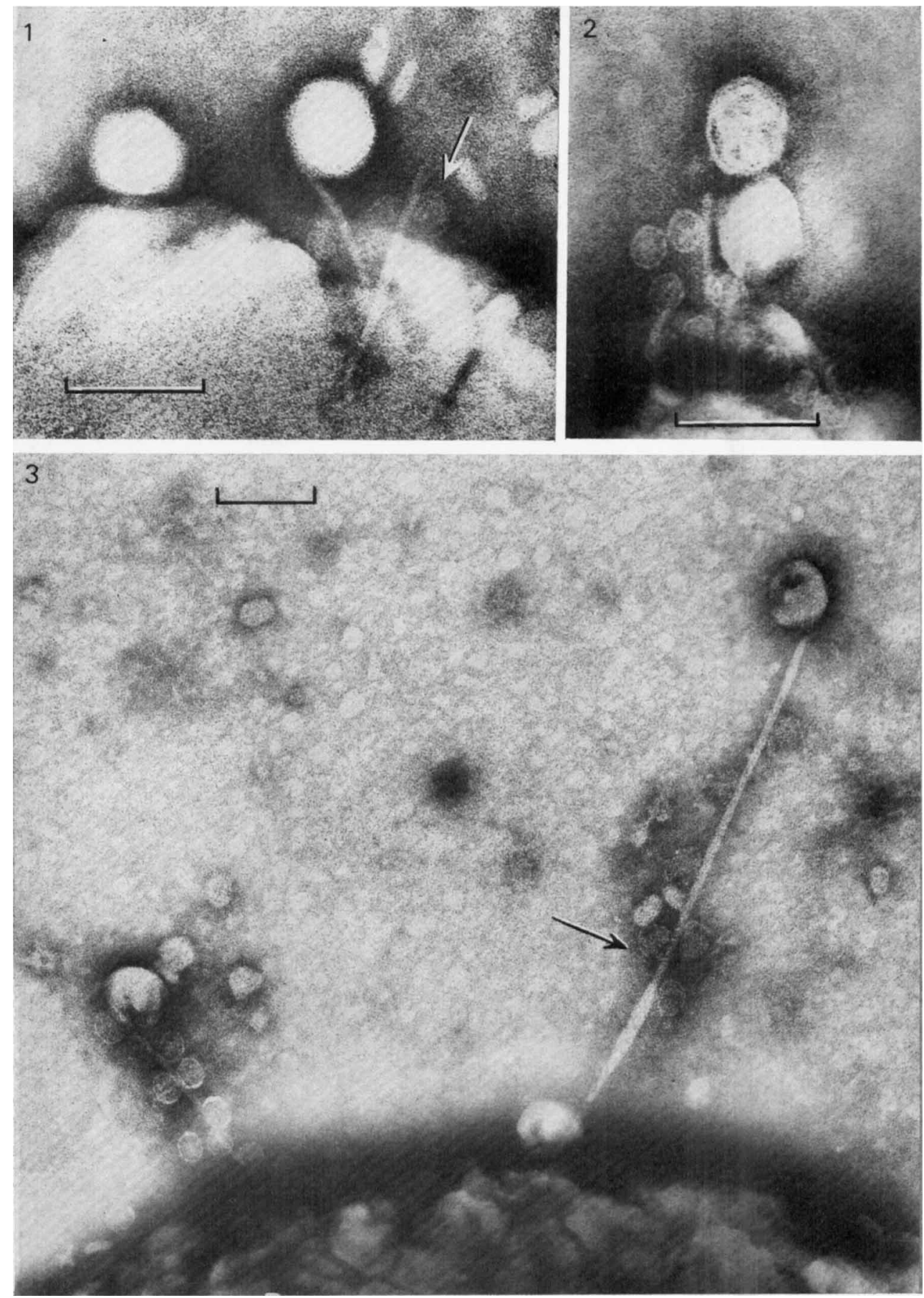

All bar markers represent $100 \mathrm{~nm}$.

Fig. I. Lipid phage PRDI virions adsorbed to Escherichia coli $\mathrm{CR}_{34}(\mathrm{RP} \mathrm{I})$. The arrow indicates RNA phage PRRI virions adsorbed to the side of a P-I pilus.

Fig. 2. Lipid phage PR4 virions adsorbed to short P-I pili on Salmonella typhimurium SQI I 39 (RPI).

Fig. 3. As Fig. 2, but showing longer pili. The arrow indicates PRRI virions. 


\section{DISCUSSION}

The results described here are essentially similar to those obtained when $\mathrm{PR}_{4}$ was adsorbed to bacteria carrying W pili (Bradley, 1976). With E. coli CR34 (RPI), the ratio of PR4 virions attached to pilus tips relative to those at the cell surface was 20:548 (i.e. 0.036). This is not very different from the ratio of 0.024 obtained when PR4 was adsorbed to $\mathrm{W}^{+}$ cells of $S$. typhimurium. In both cases the phage receptors might be located in the cell envelope, and phage adsorption to both P-I and W pilus tips might be random. However, we have demonstrated the phenomenon with P-I pili using two phages that had been independently isolated, on two bacterial species with two different preparation methods. As with $\mathrm{W}$ pili, the specificity of adsorption to the pilus tips is further demonstrated by the failure of the lipid phage virions to attach to the sides of the pili.

If P-I pili are the route of infection for the lipid phages, the large numbers of virions at the cell surface must be explained. It is possible that pilin (pilus protein) is present in the outer membrane of the cell as short stubs, not long enough for RNA phage virions to attach to the sides, but with exposed tips available for lipid phage adsorption. If this is true, the somatic receptor described by Olsen et al. (1977) should be pilin. However, this is unlikely because the protein receptor has a molecular weight of 51000 daltons/monomer, which is much greater than the 12500 daltons/monomer of another pilin (F pilin). The most plausible explanation is that the lipid phage virions attach to the tips of P-I pili, which then retract into the cell pulling them to the surface where DNA penetration is initiated. If so, RNA phages adsorbed to the sides of the pili would be required to prevent retraction as with $P$. aeruginosa pili (Bradley, I972a,b), so rendering visible the lipid phages adsorbed to the tips. DNA penetration could be mediated by the phage tail and require a secondary somatic receptor consisting of the protein described by Olsen et al. (I977).

This explanation would depend on the retractile nature of P-I pili, and we have presented evidence consistent with this: a I7-fold increase in the number of pili after PRRI adsorption. A similar increase was found with $P$. deruginosa pili after RNA phage adsorption (Bradley, I $972 a, b)$. It was shown that the pili retracted under the influence of negative staining, leaving only small numbers visible, but prior RNA phage adsorption 'locked' the pili in an extended position and caused the apparent increase in numbers. In addition, PRR J virions usually appear at the pilus bases when they are adsorbed at a frequency of $\mathrm{I}$ to 2 per pilus (Bradley, 1974). This would be their position after pilus retraction (Bradley, I972a,b).

It has now been demonstrated that PRDI and PR4 virions can adsorb to the tips of serologically unrelated pili. This ability is shared by a number of tailed $P$. aeruginosa pilus phages, which also depend on pilus retraction for infection (Bradley \& Pitt, 1974). Pili have not been found for $\mathrm{N}$ group plasmids, which also determine lipid phage sensitivity, but they may be too short to be detectable in the electron microscope.

This work was supported by the Medical Research Council of Canada (grant no. MA5608). 


\section{REFERENCES}

BRADLEY, D. E. (1972a). Shortening of Pseudomonas aeruginosa pili after RNA-phage adsorption. Journal of General Microbiology 72, 303-319.

BradLey, D. E. (1972b). Evidence for the retraction of Pseudomonas aeruginosa RNA phage pili. Biochemical and Biophysical Research Communications 47, 142-I 49.

BradLeY, D. E. (1974). Adsorption of bacteriophages specific for Pseudomonas aeruginosa R factors RPI and Ri 822. Biochemical and Biophysical Research Communications 57, 893-900.

BRADLEY, D. E. (1976). Adsorption of the R-specific bacteriophage PR4 to pili determined by a drug resistance plasmid of the W compatibility group. Journal of General Microbiology 95, 181-185.

Bradley, D. E. \& PitT, T. L. (1974). Pilus-dependence of four Pseudomonas aeruginosa bacteriophages with non-contractile tails. Journal of General Virology 24, I-I 5.

BRADLEY, D. E. \& RUTHERFoRD, E. L. (1975). Basic characterization of a lipid-containing bacteriophage specific for plasmids of the P, N, and W compatibility groups. Canadian Journal of Microbiology 2I, I52-163.

Crawford, E. M. \& Gesteland, R. F. (1964). The adsorption of bacteriophage Ri 7. Virology 22, I65-167.

JACOBY, G. A. (I977). Classification of plasmids in Pseudomonas aeruginosa. In Microbiology I 977 (in the press). Edited by D. Schlessinger. Washington, D.C.: American Society for Microbiology.

Olsen, R. H. \& ShIPleY, P. (1973). Host range and properties of the Pseudomonas aeruginosa $\mathrm{R}$ factor Ri822. Journal of Bacteriology $\mathbf{1 3}, 772-780$.

OLSEN, R. H. \& Thomas, D. D. (1973). Characteristics and purification of PRRI, an RNA phage specific for the broad host range Pseudomonas RI822 drug resistance plasmid. Journal of Virology I2, I 560-I 567.

OlSEN, R. H., SIAK, J. S. \& GRAY, R. H. (I974). Characteristics of PRDI, a plasmid-dependent broad host range DNA bacteriophage. Journal of Virology $14,689-699$.

Olsen, R. H., SiaK, J. S. \& ShIPley, P. L. (I977). Pseudomonas plasmid RPI encoded surface components: a somatic receptor for phage PRDI. In Microbiology 1977 (in the Press). Edited by D. Schlessinger. Washington, D.C.: American Society for Microbiology.

Shahrabadi, M. S., Bryan, L. E. \& VAN Den Elzen, H. M. (1975). Further properties of P-2 R-factors of Pseudomonas aeruginosa and their relationship to other plasmid groups. Canadian Journal of Microbiology 21, 592-605.

STANisich, V. (1974). The properties and host range of male-specific bacteriophages of Pseudomonas aeruginosa. Journal of General Microbiology 84, 332-342. 